fieber. Auch er hatte bereits früher die Kranklieit durchgemacht. An Bord bekam er zunächst Malaria, die günstig verlief. Seitdem nahm er auf eigene Faust hin und wieder Chinin. Eines Tages bekam er gegen A bend, nachdem er vormittags $1 \mathrm{~g}$ Chininum muriaticum genommen hatte. Schwarzwasserfieber. Wieviel Stunden zwischen der Chinineinnahme und dem Ausbruch der Krankheit lagen, ist mir in diesem Falle nicht mehr genau erinnerlich, etwa sechs bis acht. Der Fall kam zur Heilung.

Malaria kam recht häufig zur Behandlung, im ganzen 23 Fälle, von denen 13 auf die Besatzung entfielen. Der erste Maschinist, der - ich glaube - 17 Jahre nach Afrika fährt und noch nie fieberkrank gewesen war, erkrankte auf dieser Reise dreimal; ebenso ein Matrose, ein Trimmer zweinal. Recht erschwert wurde die Behandlung durch das Nichtvorhandensein eines Mikroskopes, das in vielen Fällen sehr wünschenswerth gewesen wäre.

\title{
Tropenkrankheiten.
}

\section{Ein Fall von Schwarzwasserfieber nach Euchinin.}

\section{Von Dr. W. Richter, Cottbus.}

Dr. Albert Plehn berichtet im Archiv für Schiffs- und TropenHygiene Bd. II, S. 234 und 285 , über die bisher mit dem sogenannten Euchinin (Zimmer) gemachten Erfahrungen.“ Er betont die angenehmere Art der Verabreichung, die geringere Reizung des Verdauungskanales, die schnellere Resorption und Wirkung und die weniger ungiinstige Beeinflussung des Nervensystems, welche beim Fuchinin nur in Ohrenklingen, Schwerhörigkeit und Tremor besteht, während die offenbar vom Magen reflektorisch ausgelösten Erscheinungen des sogenannten Chinin-Katers - Übclkeit, Schwere im Kopf, Schwindelgefühl - ganz fehlen oder doch nur angedeutet sind. Weiter sagt Plehn: „die Giftwirkung auf die rothen Blutkörperchen ist durchaus die gleiche wie beim Chinin“.

Diese Beobachtung findet ihre Bestätigung in einem Fall von Schwarzwasserfieber nach Euchinin, den ich als Schiffsarzt an Bord des Postdampfers "Eduard Bolılen“ (Hamburg-Westafrika) zu behandeln hatte. Da ein derartiger Fall meines Wissens bisher in der Litteratur nicht beschrieben ist, theile ich ihn kurz mit. Der Hamburger Hafenarzt - Herr Dr. Nocht - war so liebenswürdig, mich auf das Eigenartige des Falles aufmerksam zn machen, und hatte gleichzeitig die Güte, mir das nöthige Material zur Verfügung zu stellen. Ich sage Herrn Dr. Nocht hier meinen verbindlichsten Dank. Es handelte sich um einen sehr anämischen, mit einem Herzfehler behafteten jungen Mann von etwa 20 Jahren, der 8 Monate auf einer Cakao-Plantage im nördlichen Kamerun-Gebiet thätig war. Während dieser Zeit hatte er mehrmals Malaria und einmal Schwarzwasserfieber gehabt. Letzteres war nach Chinin entstanden. Am 3. April erkrankte Patient an Bord an Malaria. Er erklärte von vornherein, Chinin nicht nehmen zu wollen. Am 4. und 5. zeigte das Thermometer morgens zwischen $37,5^{\circ}$ und $38^{\circ}$ und stieg allmählich bis etwas über $40^{\circ}$ am Abend. Patient wurde sichtlich schwächer und entschloss sich am 6. zu Chinin. Er erhielt morgens $0,2 \mathrm{~g}$ Chininum muriaticum, nachdem die Temperatur zweimal mit $1 / 2$ stündigem Zwischenraum gemessen war und das erste Mal $37,4^{\circ}$, das zweite Mal $37,3^{\circ}$ betragen hatte. Das Chinin wurde gut vertragen, doch abends wieder Fieber. Am 7. morgens $1 \mathrm{~g}$ Euchinin, abends Fieber, am 8. morgens $1 \mathrm{~g}$ Euchinin.

Um $11 \mathrm{Uhr}$ vormittags bemerkt Patient, der sich leidlich wohl fühlt, dass der Harn dunkelroth aussieht. Derselbe ist stark eiweisshaltig. Patient trinkt grosse Mengen von Milch, Wasser etc. Es wird noch einmal $1 / 4$ l Harn von derselben Beschaffenheit entleert.

Um 1 Uhr mittags tritt ein halbstündiger Schüttelfrost ein. Der Puls wird klein und frequent. Die Harnabsonderung sistirt von jetzt ab gänzlich. Patient wird zum Schwitzen gebracht und trinkt weiter Thee, Sauerbrunnen u. s. w. Die Temperatur abends ist $38^{\circ}$.

Am 8. April morgens ist sehr starker Ikterus aufgetreten. Patient erhält in Abständen von je 10 Minuten 4 Esslöffel einer Mischung von 4,0 Chloroform in 250,0 Gummischleim - ohne Erfolg. Eine Spritze Aether macht keinen Eindruck. Der Puls wird immer schlechter. Patient erlıält einen warmen Einlauf und wird zwei Stunden zum Schwitzen eingewickelt - mit geringem Erfolg. Mittags setzt der Puls theilweise aus; Patient wird somnolent. Eine zweite Spritze Aether, 4 weitere Esslöffel der Chloroformmischung und 10 Tropfen Tct. Strophanti bleiben ohne Erfolg. Um 3 Uhr nachmittags erhält der schon vollständig somnolente Patient noch eine Spritze Ol. camphorat., um 3 Uhr $20 \mathrm{Mi}$ nuten tritt der Tod ein.

Ausser diesem Fall erkrankte noch ein Passagier an Schwarzwasser- 